\title{
Clinico-Laboratory Profile and Immediate Outcomes of Hyperbilirubinemic Babies Admitted in Kanti Children Hospital
}

\author{
Nepal D', Banstola D², Dhakal AK ${ }^{3}$, Mishra U4 , Mahaseth $C^{5}$
}

${ }^{1}$ Dr. Nepal Deepeshwara MBBS, MD, WHO Fellow in Neonatology, Senior Medical Officer, Kanti Children Hospital Kathmandu, ${ }^{2}$ Dr. Banstola Dinesh Asst. Professor Department of Physiology Tribhuwan University Teaching Hospital, ${ }^{3}$ Dr. Ajaya Kumar Dhakal Paediatric Resident, TUTH, ${ }^{4}$ Dr. Udbhabhat Mishra Paediatric Resident, National Acedemy of Medical Science, ${ }^{5}$ Dr. Chandeshawar Mahaseth, Professor of Paediatrics National Academy of Medical Science, Bir Hospital, Kathmandu, Nepal.

Address for Correspondence: Dr. Deepeshwara Nepal, E-mail: dnepal123@hotmail.com

\begin{abstract}
Introduction: Jaundice is an important problem in the neonatal period especially in the first week of life. Our objective of the study is to find out the immediate outcome of hyperbilirubinemic babies admitted in Kanti Children Hospital. Methodology: This is a retrospective study and carried out in tertiary care paediatric hospital. Results: Altogether 73 babies were enrolled in the study. Male babies outnumbered the female $(72.6 \%$ vs. $27.4 \%)$. Only $2.4 \%$ babies were near-term. LBW babies constitute $19.2 \%$ of the study population. $86.3 \%$ of babies also have clinical sepses as defined by WHO criteria. Almost half of the babies have mild hyperbilirubinemia (15-19.9 mg/dl). Most of the babies $(94.5 \%)$ improved and the mortality was $5.5 \%$. Conclusion: Healthy term babies with a serum bilirubin $<17 \mathrm{mg} / \mathrm{dl}$ should not be admitted for routinely as they do not need phototherapy. Phototherapy is effective in most of the time, but exchange transfusion should also be carried out when phototherapy fails. Causes of hyperbilirubinemia should be searched extensively especially to rule out haemolysis.
\end{abstract}

Key words: hyperbilirubinemia, kernicterus, neonates, phototherapy.

\section{Introduction}

aundice is an important problem in the newborn period, especially in the first week of life. It is a cause of concern for the physician and a source of anxiety for the parents. Jaundice in the newborn is a unique problem because most of the time it is unconjugated hyperbilirubinemia which when elevated at pathological range is potentially toxic to infants developing brain and may lead to kernicterus. Most cases of jaundice in the newborn are benign, but because of the potential toxicity of bilirubin, newborn infant must be monitored to identify those who might develop severe hyperbilirubinemia and in rare cases acute bilirubin encephalopathy or kernicterus ${ }^{1}$. Nearly $60 \%$ of the terms neonates become visibly jaundiced in the first week of life ${ }^{2}$. Even higher percentages of preterm infants are at risk of developing jaundice. National Neonatal Perinatal Database
Network of India reported that $5.7 \%$ neonates required phototherapy for jaundice ${ }^{3}$. Of the infants defined as hyperbilirubinemia, the maximum level of serum total bilirubin (STB) exceeded $20 \mathrm{mg} / \mathrm{dl}(342 \mu \mathrm{mol} / \mathrm{L})$ in $2 \%$ representing $0.25 \%$ of all the births ${ }^{2}$. Approximately 2 $4 \%$ of exclusively breastfed term babies have jaundice in excess of $10 \mathrm{mg} / \mathrm{dl}$ in the first week of life ${ }^{4}$.

Hyperbilirubinemia in newborn is defined as need for phototherapy as stated by American Academy of Pediatrics (AAP) guidelines ${ }^{5}$. Chemical hyperbilirubinemia, defined as a total serum bilirubin level of $2.0 \mathrm{mg} / \mathrm{dl}(34 \mu \mathrm{mol} / \mathrm{L})$ or more is virtually universal in newborn during the first week of life $^{3}$. Traditionally a distinction has been made between benign physiologic jaundice and hyperbilirubinemia which is either pathologic in origin or severe enough to be considered deserving 
of further evaluation and intervention. The latter entity has been called "non physiologic" or pathologic jaundice if the concentration of bilirubin exceeds $5 \mathrm{mg} / \mathrm{dl}$ (86 $\mu \mathrm{mol} / \mathrm{L})$ on the first day of life in a term neonate, $10 \mathrm{mg} /$ dl $(171 \mu \mathrm{mol} / \mathrm{L})$ in second day, or $12-13 \mathrm{mg} / \mathrm{dl}$ (205$222 \mu \mathrm{mol} / \mathrm{L}$ ) thereafter, based on data from the National Collaborative Perinatal Project total serum bilirubin elevation exceeding $17 \mathrm{Mg} / \mathrm{dl}(291 \mu \mathrm{mol} / \mathrm{L})$ should be presumed pathologic and warrants investigation for a cause and possible therapeutic intervention such as pototherapy ${ }^{6,7}$. Low concentration of bilirubin may have some antioxidant benefits, suggesting it should not be completely eliminated ${ }^{8}$. The risk of developing Kernicterus is generally confined in neonates whose total serum bilirubin concentration rises to values greater than $20-24 \mathrm{mg} / \mathrm{dl}(340-408 \mu \mathrm{mol} / \mathrm{L})^{9}$. Because most of the dangerous or extreme hyperbilirubinemia are related to haemolysis, identification of overproduction of bilirubin is useful in the early identification of bilirubin toxicity ${ }^{1}$. Kanti Children Hospital is the only tertiary care Hospital in the country with neonatal intensive care facilities where most of the sick neonates are referred for appropriate care. Neo-natal Jaundice (NNJ) is one of the common reasons for admission and treatment. There has been no recent study on NNJ at this hospital so it was considered to be worthful doing this study. Objectives of this study were to find out the immediate outcomes of hyperbilirubinemic babies and also to find out the associated co morbid condition with neonatal Jaundice.

\section{Methodology}

This is a retrospective observational study. It has been done in a tertiary care paediatric hospital (Kanti Children Hospital). Subjects and methodology: All terms and near terms (35-36weeks) neonates admitted to Kanti Children Hospital with the diagnosis of neonatal jaundice (NNJ) and total serum bilirubin level $>15 \mathrm{mg} / \mathrm{dl}$ were assessed for the maximum level of bilirubin. Those babies who were admitted to Kanti Children Hospital either in NIMCU (Neonatal Intermediate Care Unit) or in NICU from the 1st of March to the 1st of June 2009 were included in the study.

Measurements of s.bilirubin level were done by two biochemical methods; first the High Performance Liquid Chromatography (HPLC) method, which remains the gold standard method for bilirubin measurement and measures total as well as direct fraction of bilirubin based on the Van den Bergh reaction. Secondly the twin beam microbilimeter based on spectro photometry which estimates unconjugated bilirubin only.

All the neonates having hyperbilirubinaemia were treated with phototherapy; those babies who also have sepsis including meningitis also received antibiotics. Immediate outcomes were studied in the form of complete recovery, recovered with neurological impairments and death. Data were analysed by using SPSS software.

\section{Results}

All together 361 neonates had been admitted in Kanti Children Hospital during the study period. Among them 73 babies fulfilled the study criteria for enrolment which constituted $20 \%$ of neonatal morbidity. Male babies outnumbered female babies i.e. 53 (72.6\%) were male babies. 40 (54.8\%) babies were born to primi Para mother. Only 6(8.2\%) babies were near-term. LBW babies constituted 14 (19.2\%). Only 17 (23.3\%) babies were delivered at home.

Clinical sepsis as defined by WHO criteria was found in $86.3 \%$ of babies and among them $9.6 \%$ cases were culture proven. Almost half of the babies had only moderate hyperbilirubinaemia (15-19.9mg/dl). Nearly $1 / 3$ rd $(32.9 \%)$ babies were ABO incompatible and $4.1 \%$ babies were Rh incompatible. Most of the babies' i.e. 69 $(94.5 \%)$ improved completely and death was observed in only $4(5.5 \%)$ babies.

As sepsis is the commonest cause of admission in neonatal period in our hospital, every baby is screened for sepsis; a lumbar puncture is done in symptomatic sepsis. Fig. 1 shows the percentage of babies with clinical sepsis, Septic screen positive sepsis, and culture proven sepsis, meningitis and birth asphyxia in hyperbilirubinemic babies.

Fig. 2 shows maximum level of s.bilirubin during hospital stay, more than two third babies have mild hyperbilirubinemia i.e. their bilirubin falls in between $15-19.9 \mathrm{mg} \%$,only $3 \%$ of babies have maximum rise of serum bilirubin i.e. $>30 \mathrm{mg} \%$. 
Table1: Showing Demographic Variables of the Study Population.

\begin{tabular}{|l|c|c|}
\hline Variables & Number & Percentage \\
\hline Gender & 53 & 72.6 \\
a.Male & 20 & 27.4 \\
b.Female & & 54.8 \\
\hline Gravida & 40 & 45.2 \\
a.Primi & 33 & 8.2 \\
b.Multi & & 91.8 \\
\hline Gestation age & 6 & 19.2 \\
a.Near-term & 67 & 80.8 \\
b.Term & & 4.1 \\
\hline Birth weight & 14 & 27.4 \\
a.LBW & 59 & 54.8 \\
b.Normal & & 13.7 \\
\hline Age at the time of admission & 3 & \\
a.Within 24 hours & 20 & 23.3 \\
b.24-72 hours & 40 & 76.7 \\
c.72hours-7 days & 10 & 87.7 \\
d.>7days & & 4.1 \\
\hline Place of delivery & 17 & \\
a.Home & 56 & \\
b.Health facilities & & \\
\hline Mode of delivery & 64 & \\
a.Spontaneous Vaginal Delivery & 6 & \\
b.Caesarean section & 3 & \\
c.Instrumental & & \\
\hline
\end{tabular}

Table 2: Early outcomes of Hyperbilirubinemic Babies at the time of discharge along with its Biosocial Characters.

\begin{tabular}{|c|c|c|c|c|}
\hline Variables & Total cases & Improved cases & Death cases & $p$ - value \\
\hline $\begin{array}{l}\text { Sex } \\
\text { Male } \\
\text { Female }\end{array}$ & $\begin{array}{l}53(72.6 \%) \\
20(27.6 \%)\end{array}$ & $\begin{array}{l}50 \\
19\end{array}$ & $\begin{array}{l}3 \\
1\end{array}$ & 1.0 \\
\hline $\begin{array}{l}\text { Birth weight } \\
\text { LBW } \\
\text { NBW }\end{array}$ & $\begin{array}{l}14(19.2 \%) \\
59(80.8 \%)\end{array}$ & $\begin{array}{l}13 \\
56\end{array}$ & $\begin{array}{l}1 \\
3 \\
\end{array}$ & 1.0 \\
\hline $\begin{array}{l}\text { Place of delivery } \\
\text { Home } \\
\text { Health facilities }\end{array}$ & $\begin{array}{l}17(23.3 \%) \\
56(76.6 \%)\end{array}$ & $\begin{array}{l}16 \\
53\end{array}$ & $\begin{array}{l}1 \\
3\end{array}$ & 1.0 \\
\hline $\begin{array}{l}\text { Seizure } \\
\text { Present } \\
\text { Absent }\end{array}$ & $\begin{array}{c}2(2.7 \%) \\
71(97.3 \%)\end{array}$ & $\begin{array}{c}1 \\
68\end{array}$ & $\begin{array}{l}1 \\
3\end{array}$ & 0.107 \\
\hline $\begin{array}{l}\text { Birth Asphyxia } \\
\text { Present } \\
\text { Absent }\end{array}$ & $\begin{array}{c}1(1.4 \%) \\
72(98.6 \%)\end{array}$ & $\begin{array}{c}0 \\
69\end{array}$ & $\begin{array}{l}1 \\
3 \\
\end{array}$ & 0.055 \\
\hline $\begin{array}{l}\text { Septic screen+ve sepsis } \\
\text { Present } \\
\text { Absent }\end{array}$ & $\begin{array}{l}34(46.6 \%) \\
39(53.4 \%)\end{array}$ & $\begin{array}{l}32 \\
37\end{array}$ & $\begin{array}{l}2 \\
2\end{array}$ & 1.0 \\
\hline
\end{tabular}

None of the above variables are significantly associated with mortality except birth asphyxia. 


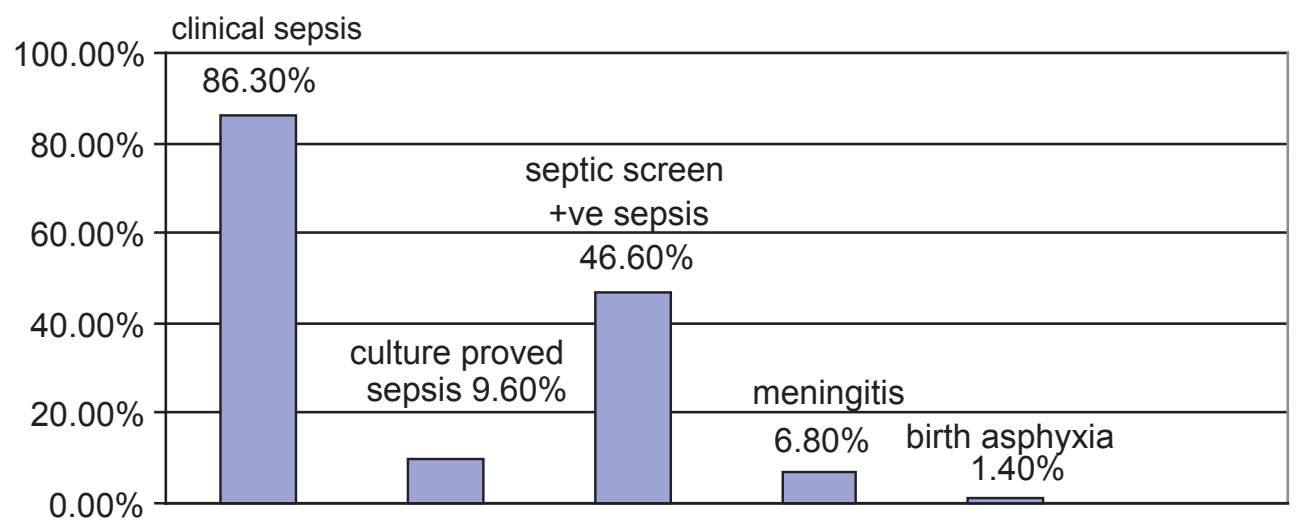

Fig. 1: Showing Clinical Sepsis along with Hyperbilirubinemia.

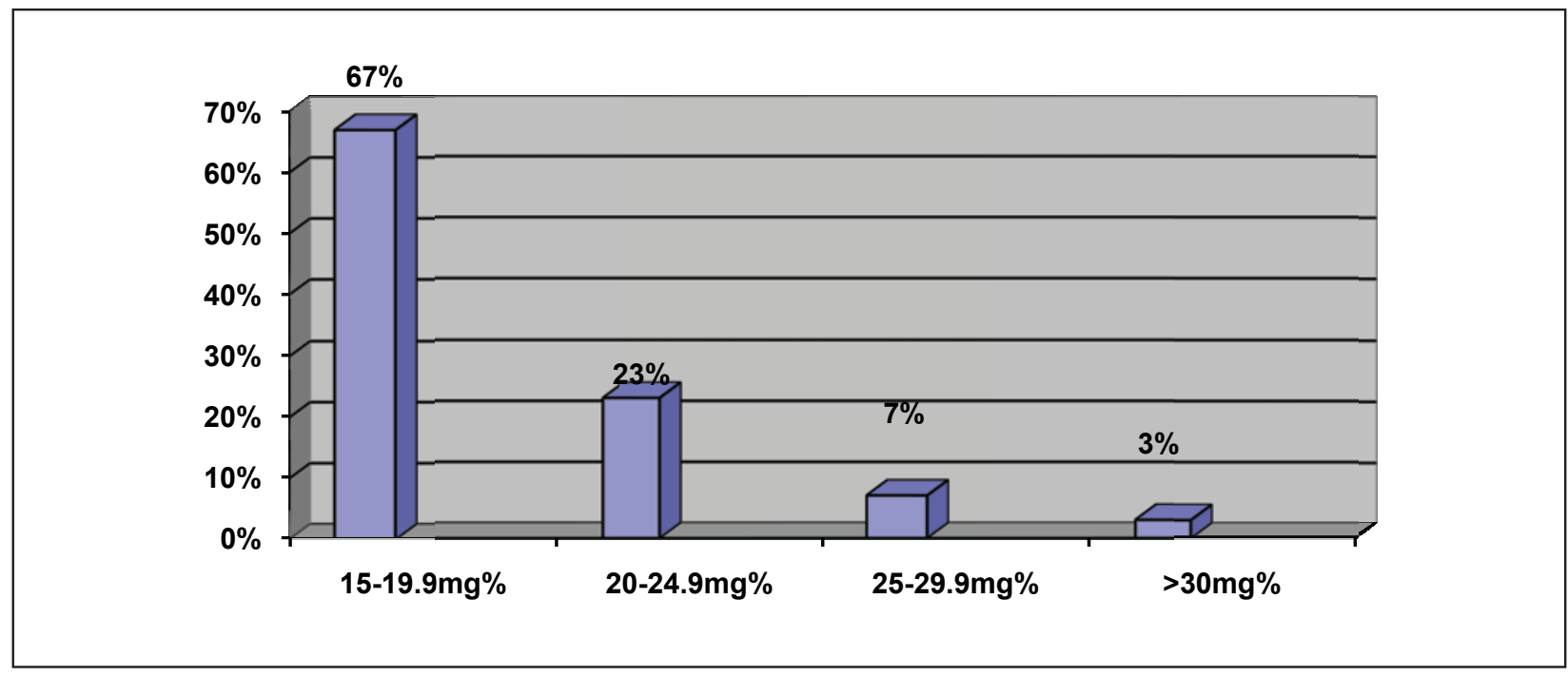

Fig. 2: Showing Percentage of Babies with Maximum Level of Serum Bilirubin.

\section{Discussion}

Hyperbilirubinemia is one of the most common causes of hospital admission in nurseries. Although jaundice is a benign condition; infants must be monitored to identify those who might develop acute bilirubin encephalopathy or kernicterus. Although kernicterus should almost always be preventable, cases continue to occur in infants of 35 or more weeks' gestation.

The following are the key elements of the recommendation by AAP guideline: Every clinician should:

1) Promote and support successful breast feeding.

2) Perform a systematic assessment before discharge for the risk of severe hyperbilirubinemia.

3) Provide early and focussed follow-up based on the risk assessment.
4) When indicated, treat newborn with phototherapy or exchange transfusion to prevent the development of severe hyperbilirubinemia and possible bilirubin encephalopathy ${ }^{4}$.

Infants with 35-37 weeks of gestation were usually treated in well infant nurseries as if they were term infants and managed no differently from those of $\geq 38$ weeks' gestation with respect to diagnosis, treatment and follow-up of hyperbilirubinemia ${ }^{10}$. However in another study of infants born at 37weeks' gestation were much more likely (4 times) to develop a serum bilirubin level of $\geq 13 \mathrm{mg} / \mathrm{dl}$ than those born to 40 weeks of gestation ${ }^{11}$. AAP guidelines (subcommittee on hyperbilirubinemia) recommend that infants at medium risk ( $\geq 38$ weeks + risk factors or 35-37 6/7 weeks and well) and infant at higher risk (35-37 6/7weeks +risk factors) should be 
treated at lower bilirubin level as compared to infants at lower risk ( $\geq 38$ weeks and well) in order to prevent kernicterus ${ }^{4}$.

There is a strong association between breastfeeding and jaundice in the healthy newborn infants. We have observed that $93.6 \%$ hyperbilirubinaemic babies were on exclusive breastfeeding. This might be due to universal breastfeeding practices in Nepal. Similar finding was observed by Jeffeyet al. He found that of infants for whom no causes for hyperbilirubinaemia was found, $82.7 \%$ were breastfed compared to $46.9 \%$ in control group $(p<.0001)^{12}$.

We observed that maximum number $(67.1 \%)$ of infants' peak serum bilirubin fell in the range of 15-19.9 $\mathrm{mg} / \mathrm{dl}$, and the mean serum bilirubin was $400 \mu \mathrm{mol} / \mathrm{L}$. Similar result was observed by Sgro et al who found that mean peak serum bilirubin was $471 \mu \mathrm{mol} / \mathrm{L}^{13}$. In our study $\mathrm{ABO}$ incompability was found in $32.9 \%$ of cases while in another study it was $51.6 \%{ }^{10}$. In our study culture proved sepsis was found in $9.6 \%$ of hyperbilirubinemic babies, where as in the study by Awasthi et al culture positive was seen in only $1.1 \%^{14}$. However Narang et al mention that sepsis contributed to only $4.49 \%$ cases of hyperbilirubinemia ${ }^{15}$. In our study hyperbilirubinemia was more common in male babies as compared to female babies $(72.6 \%$ vs. $27.4 \%)$, similar finding were observed by Mantani et al (62\% vs. $38 \%)$ and Sharma et al $(1.3: 1)^{16,17}$. Interestingly we observed that peak serum bilirubin or total serum bilirubin did not have any correlation with the final outcome which was also observed by Mantani et al ${ }^{16}$.

\section{Conclusion}

To conclude hyperbilirubinemia is one of the most common causes of hospital admission in our nursery and it is associated with various other clinical morbidities. Healthy term babies with a serum bilirubin $<17 \mathrm{mg} / \mathrm{dl}$ should not be admitted for routinely as they do not need phototherapy. Phototherapy is effective in most of the time, but exchange transfusion should also be carried out when phototherapy fails. Causes of hyperbilirubinemia should be searched extensively especially to rule out haemolysis ( $\mathrm{ABO}$ and $\mathrm{RH}$ typing should be routinely done along with Direct Coombs Test, peripheral smear, retics count and G6PD screening). Detailed neurological examination during admission and at discharge should be recorded.

\section{Acknowledgement: None.}

Limitations of this study: The small sample size and the study being retrospective are two main drawbacks of this study.
Funding: None.

Conflict of Interest: None.

\section{References}

1. American Academy of Pediatrics, Subcommittee on Hyperbilirubinemia.Clinical practice guidelines Management of hyperbilirubinemia in Newborn infant 35 or more weeks of gestation. Pediatr. 2004; 114:297-16.

2. Madan A, MaCMahon JR, DK Stevenson. Neonatal Hyperbilirubinemia.In HW Taeush, Ballard RA Gleason CA, Eds: Avery's Diseases of the Newborn. Philadelphia: Saunders; 2005:1226-56.

3. National Neonatal Forum of India. National Neonatal Perinatal Database-Report for 20022003.New Delhi: NNF India; 2005.

4. Clarkson JE, Cowan JO, and Herbison GP.Jaundice in full term healthy neonates: A population study. Aust Pediatr J 1984; 20:303-8.

5. Maisles MJ,Balter RD,Bhutani V,et.al.Management of hyperbilirubinemia in the newborn infant 35 or more weeks of gestation. Pediatr.2004; 114:297-316.

6. Hardy JB, Drage JS, Jackson EL.The first year of life. The Collaborative Perinatal Project of the National Institute of Neurological \& communicative Disorder of stroke.Baltimorre, Johns Hopkins University Press, 1979; p104.

7. Maisels MJ, Gifford K.Normal serum bilirubin level in newborns and effect of breast-feeding. Pediatr. 1986; 78: 837-43.

8. Stevenson DK, Fanaroff AA, Maisles MJ, et.al. Prediction of hyperbilirubinemia in near-term and term Infants.Pediatr. 2000; 108:31-39.

9. Gopinathan V,Millar NJ,Mifner AD, Rice-Evans CA. Bilirubin and ascorbate antioxidant activity in neonatal plasma.FEBS lett 1994;349:197-200.

10. Koch CA, Jones DV, Dine MS et.al. Hyperbilirubinemia in premature infants: a followup study. Pediatr.1959;55:23-9

11. Gale R, Seidman DS, Dollberg S, Stevenson DK.epidemiology of neonatal Jaundice in the Jerusalem population. Pediatr Gastroenterol Nutr.1990; 10:82-86.

12. M.Jeffy, Maisles MB, Bachard Kathleen, Giffard RNC. Normal serum bilirubin levels in the newborn and the effect of breast-feeding. Pediatr. 1986; 78:837-43. 
13. Michael S, Douglas $C$ and Shah V. Incidence and causes of severe neonatal hyperbilirubinemia in Canada. Can. Med. Assoc. J., Sep 2006; 175: 587 - 590 ; doi:10.1503/cmaj.060328

14. Awasthi $S$ and Rehaman H.Early prediction of Neonatal hyperbilirubinemia. Indian $J$ Pediatr. 1998; 65:131-9.

15. Narang A, Kumar $P$, and Kumar R.Neoanatal Jaundice in very low birth weight babies. Indian $J$ Pediatr 2001; 68:307-9.
16. Mantani M, Patel A, Renge R, Kulkarni H.Prognostic value of direct bilirubin in Neonatal Hyperbiliruinemia. Indian J Pediatr 2007; 79:81922.

17. Sharma P, Chhangani N.P, Meena KR,Jora R, Sharma N, Gupta BD. Brainstem Evoked Response Audiometry (BAER) in Neonates with hyperbilirubinemia. Indian J. Pediatr 2006; 73:41316. 